\title{
Sequence Modeling and Calculations in the Design of Revolving Clamp Assembly
}

\author{
E. E. Jumbo \\ Department of Mechanical/ Marine Engineering, Niger Delta University, Wilberforce Island, Bayelsa State, \\ Nigeria.
}

\begin{abstract}
The study has considered the fundamental calculations in the design of revolving clamp assembly; which in any standard manufacturing environment is not only critical but dependable. This implies that the revolving clamp assembly is a very important work tool in any well-equipped workshop. The characteristics of this clamp compare well with the intended purpose of its design. Many types of clamps exist with limited scope of use and application; but the revolving clamp applies some flexibility for which a particular workpiece could be positioned and worked upon from different angles. The study also conducted a calculation of the stress capacity of the revolving clamp assembly, where it observed that the surface or stress area of a clamp device plays a crucial role its work holding capability. The yield stress was also determined alongside its bending and crushing stress.
\end{abstract}

Keywords: tensile stress, axial load, permissible stress, crushing stress, residual tolerance factor.

\section{Introduction}

The device under consideration is a simple machine with the capability of holding a work piece firmly for purposes of further machine work or finishing treatments. Its design is dependent on the varying nature of task and its multifunctional, multi-tasking attributes. It is a quick hold-down of workpiece with hand tightening; then loosen and revolve out of the way. It saves time for moderate-duty clamping. It is made of malleable cast iron body. Case-hardened swivel pad uses "true-center" feature to maintain an even in-line pressure on workpiece.

These characteristics are the product of mathematical modeling employed to translate systemic sequences and mechanisms into machine capable activities [1]. The design thus makes references to materials and there IS specifications as support base to enhance the model [2] and specifically applied the design syntax using an M16 x 1.5 bolts (16mm diameter bolt with preload stress of 10,000-25,000psi depending on ingrained material quality)

Thus, solutions to practical engineering problems begin with theoretical mathematical models which are intended to provide limits and tolerances hence guaranteeing machine workability and efficiency. In this regard, engineering designs are based on practical needs which engender research and consequent mathematical models of the problem and anticipated solutions.

In the sections that follow below, the design parameters, modeling sequence and calculations giving rise to the revolving clamp inserted below would be considered.

\section{Guidelines For Design And Assembly}

In engineering design, certain conventional guidelines are necessary to ensure standardization [1]. Such guidelines are very crucial to the production of engineered hardware. It should be noted that the critical essence of these guidelines is to reduce cost and keep the product competitive. Thus, when these guidelines are carefully followed, then integration of components into subassemblies and final products is easier. These guidelines are summarized as follows;

a) Reduce the number and types of parts used in product manufacturing, so that fewer steps and fixtures are required. This approach reduces assembly cost. This approach is referred to as value engineering.

b) Parts to be assembled should have high degree of symmetry or a high degree of asymmetry. They should be designed such that they would not be installed incorrectly. Or such that they do not require locating, aligning, or adjusting.

c) Designs should allow parts to be assembled without obstruction or the lack of a direct line of sight.

\section{TENSILE STRESS}

Due to bolt tightening (for stem and cap screw).

Experiments have shown that there exits an initial tension in the stem bolt during tightening [3] and experientially, could be found by the relation; 


$$
\boldsymbol{P}_{\boldsymbol{i}}=1420 \mathrm{~d} \mathrm{~N}
$$

where: $\boldsymbol{P}_{\boldsymbol{i}}=$ initial tension in a bolt

$\boldsymbol{d}=$ nominal diameter of the bolt $=16 \mathrm{~mm}$ (as per design dimension)

Thus, $\boldsymbol{P}_{\boldsymbol{i}}=1420 \times 16=22720 \mathrm{~N}$

For purpose of this design, the initial tension on the stem should not exceed $22720 \mathrm{~N}$. It should be noted that this $\boldsymbol{P}_{\boldsymbol{i}}$ value includes factor of safety and other material reinforcement considerations which are normally incorporated at the point of casting, forging and other material forming techniques of the components of the machine. Thus, special purpose bolts of this nature are adequately stressed during formation and treatment processes [4], [5]. These treatments are made before thread cutting and enables preload condition determinations and machine design assessments.

\section{STRESS AREA}

Area of stem bolt under load engagement situation [7];

Stress Area $=\pi / 4\left(\underline{\mathrm{d}}_{\mathrm{p}}+\frac{\mathrm{d}_{\mathrm{c}}}{2}\right)^{2}$

Where: $d_{p}=$ pitch diameter $=14.701$

$\mathrm{d}_{\mathrm{c}}=$ Core or minor diameter $=13.546$

$$
\begin{aligned}
& \left.=\frac{3.142}{4} \frac{(14.701+13.546}{2}\right)^{2} \\
& =362.1 \mathrm{~mm}^{2}
\end{aligned}
$$

The above calculation shows that the area of work for which the stem of this revolving clamp could be used should not exceed $362.1 \mathrm{~mm}^{2}$. This is because a proportional relationship exists between the active load and the specific cross-sectional area impacted by the load. This is referred to as, true stress [7].

\section{Compressing Or Crushing Stress On The Threads}

This effective stress, has to do with the value of the stress between the threads which combine to transfer the needed force to the work piece under the stem. This stress is obtained by the relation;

$$
f_{c}=\frac{\mathrm{P}}{\pi\left(\mathrm{d}^{2}-\mathrm{d}_{\mathrm{c}}^{2}\right) n}
$$

where : $d=$ major diameter

$$
\begin{aligned}
& \mathrm{d}_{\mathrm{c}}=\text { minor diameter } \\
& \mathrm{n}=\text { number of threads in engagement } \\
& \mathrm{P}=\text { maximum safe axial load }
\end{aligned}
$$

Keeping the equation above in view, we have to determine the maximum safe axial load $\boldsymbol{P}_{f}$, which must sustain the stress from the stem.

Thus: Axial load, or resistive upward force $\boldsymbol{P}_{\boldsymbol{f}}=$ Permissible stress $\mathrm{x}$ cross sectional area at the bottom of the thread (which transmit force to the pad)

Here, Permissible Stress, $\boldsymbol{P}_{\boldsymbol{s}}=\frac{\text { Tension in bolt }(\mathrm{N})}{\text { Stress Area }\left(\mathrm{mm}^{2}\right)}=\frac{22720}{362.1}$

$$
=62.7 \text { N.mm }{ }^{2}
$$

Since cross sectional area of the bottom (pad) has been found to be $362.1 \mathrm{~mm}^{2}$, then;

Axial load or resistive upward force, $\boldsymbol{P}_{f}=62.7 \times 362.1=\underline{22703.7 \mathrm{~N}}$

\section{REVOLVING CLAMP DESIGN SYNTAX}

From the calculations above, it should be noted that:

1. the tension in the stem bolt required to firmly hold the work piece is $22720 \mathrm{~N}$

2. the Axial load or resistive upward force (in the sense of this design) has a value of $22703.7 \mathrm{~N}$ 
This implies that:

The Tension required (to hold the work piece) - Resistive upward force (of work piece) $=$ Residual Tolerance Factor $\boldsymbol{R}_{t f}=22720-22703.7=16.3 \mathrm{~N}$.

It should be thus noted that this residual tolerance factor is marginal and acts like a machine tolerance or error acceptable level, beyond which the stem may fail. However, even though this design has shown this tolerance factor to be near negligible values, machine design efficiencies could be used to enhance and possibly increase it [8].

\section{BENDING STRESS}

This is applicable when the surface under the pad is not perfectly parallel to the stem axis. It is therefore a precursory step to the operation of the device in that if the work piece to be engaged is not perfectly parallel to the pad, the understated expression could be used to determine the bending action, should it be subjected to a bending action. Consequently, the bending stress induced in the shank of the bolt is given as;

$$
\begin{aligned}
& \begin{array}{l}
f=\frac{\chi \cdot E}{2 l} \\
\text { Where: } \chi=\text { difference in height between the extreme corners of the pad } \\
\quad l=\text { length of the shank of the stem. } \\
\text { E }=\text { Young's Modulus for the material of the stem }
\end{array}
\end{aligned}
$$

The foregoing therefore implies that bending stress can only be determined upon measurement of the difference in work piece deviation from effective area of the pad and length of the shank. The data received could be computed into the formula above to obtain the bending stress.

\section{DISCUSSIONS}

It has been observed [6] that effective workpiece holding devices should aim at:

i) flexibility and maneuverability

ii) firm grip of workpiece during machining

iii) accurate positioning of workpiece by sufficient clamping

In view of the foregoing, the calculations for this design has to do with laboratory and workshop practice, for which the paper posits that in laboratory or workshop conditions and under speed machining situations; workpiece materials are better held by work tools that should be flexible, (when required). Accordingly, work holding devices are important to ensure that the workpiece materials are held properly in the determined positions [6]. Clamps also keep the workpiece from rotating or slipping when work is done on it.

This imply that the proper design and construction of the flexible work holding devices and fixtures is essential to the operation of advanced manufacturing systems; especially if precision is a critical concern to the entire manufacturing process. Thus, a clamping force is required to hold the workpiece properly and accurately and must maintain its location with a precise and sufficient fastening energy during machining operation.

Further, experimental data generated from the Advanced Manufacturing Engineering Laboratory (AME-lab) of the Niger Delta University in tensile test experiments with respect to this paper, resulted the table and figures below:

Table 1- Experimental Data for Residual Tolerance Factor Determination for M12-M20 bolt

\begin{tabular}{|l|l|l|l|l|l|}
\hline $\begin{array}{l}\text { Nominal size d } \\
(\mathrm{mm})\end{array}$ & $\begin{array}{l}\text { Initial tension in the } \\
\text { bolt } P_{i}(\mathrm{~N})\end{array}$ & $\begin{array}{l}\text { Permissible stress } P_{s} \\
\left(\mathrm{Nmm}^{2}\right)\end{array}$ & $\begin{array}{l}\text { Axial load } p_{f} \\
(\mathrm{~N})\end{array}$ & $\begin{array}{l}\text { Tolerance factor } \\
R_{t f}(\mathrm{~N})\end{array}$ & $\begin{array}{l}\text { Permissible } \\
\text { differentials }\end{array}$ \\
\hline M $12 \times 1.5$ & 17040 & 47.0 & 17018.70 & 21.3 & \\
\hline M $14 \times 1.5$ & 19880 & 54.9 & 19879.29 & 0.71 & - \\
\hline M $16 \times 1.5$ & 22720 & 62.7 & 22703.70 & 16.3 & 7.9 \\
\hline M $18 \times 1.5$ & 25560 & 70.5 & 25528.05 & 31.95 & 7.8 \\
\hline M $20 \times 1.5$ & 28400 & 78.4 & 28388.64 & 11.36 & 7.8 \\
\hline
\end{tabular}



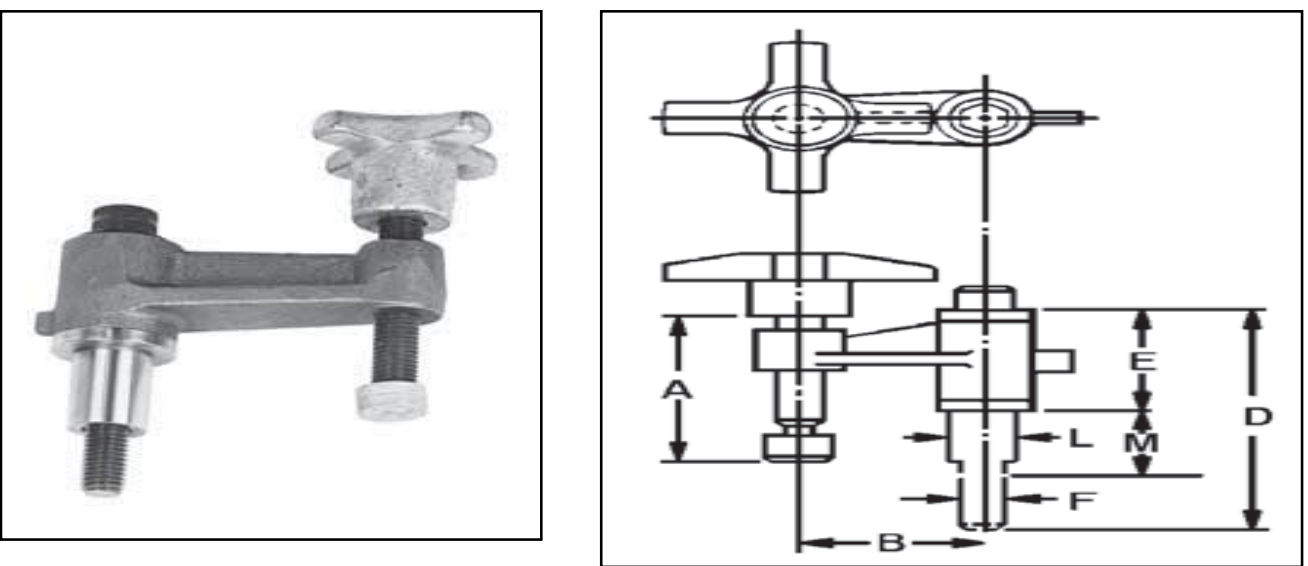

Fig 1: Revolving clamp assembly Fig 2 : Sectional view of revolving clamp assembly (Courtesy: AME-Lab, Niger Delta University)

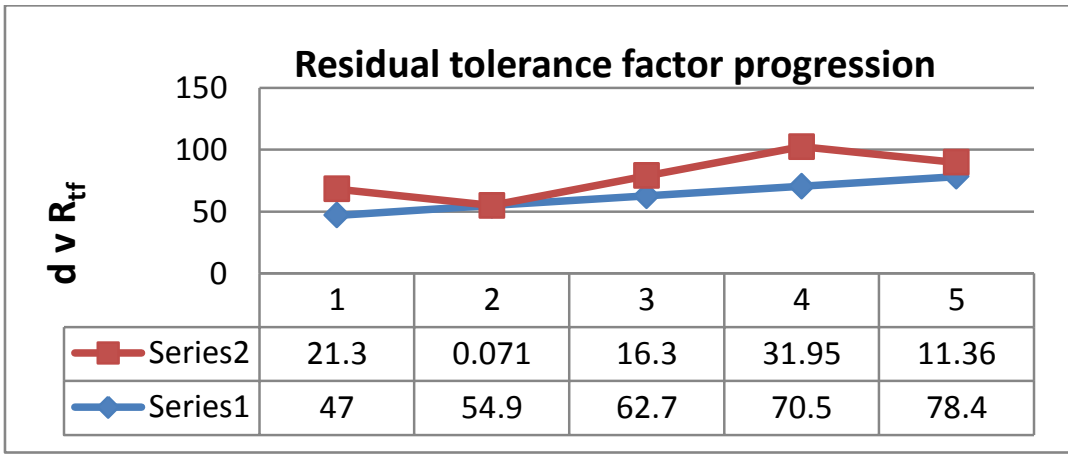

Fig. 3- residual tolerance graph $\left(P_{s} \vee R_{t f}\right)$

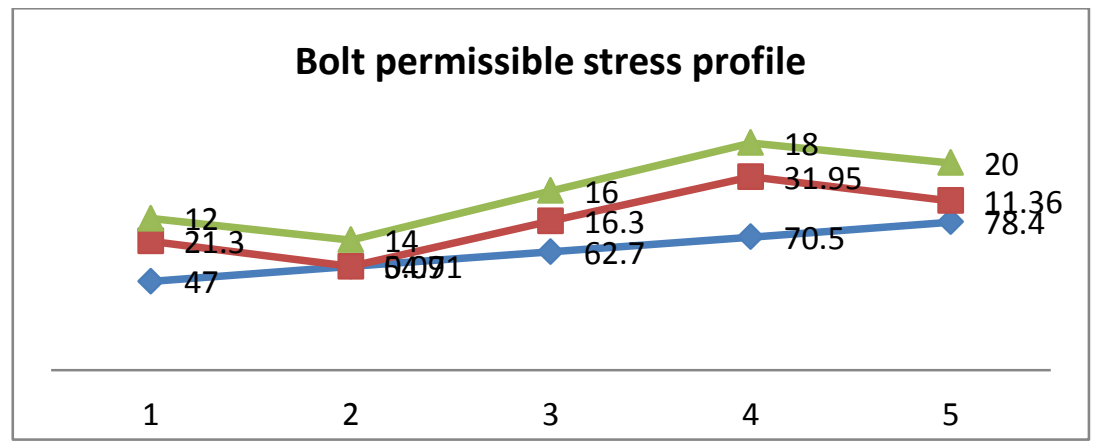

Fig 4-permissible stress profile $\left(d v R_{t f} v P_{s}\right)$

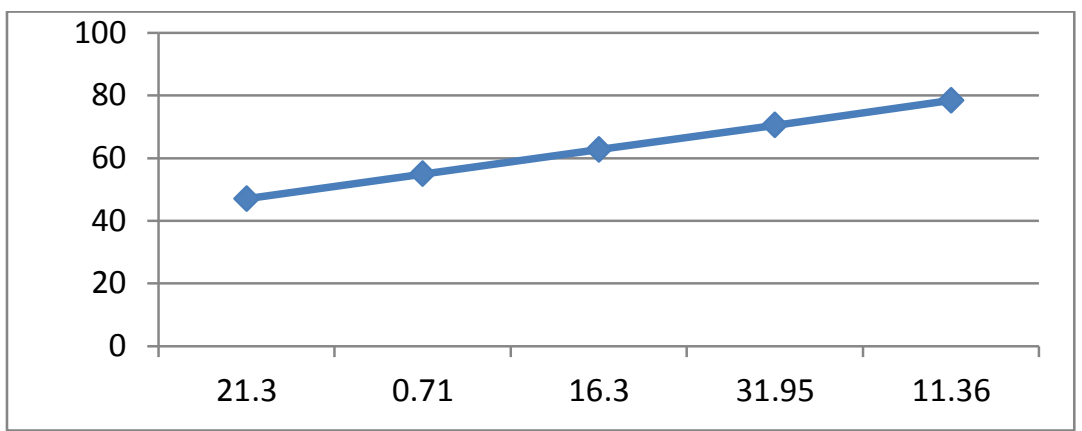

Fig. 5- reverse residual tolerance $\left(P_{s} v R_{t f}\right)^{-1}$

It could thus be noted that a reverse of the residual factor progression graph (i.e. Fig 3) of the experiment produced a straight line originating from and corresponding to $47.2 \mathrm{~N} . \mathrm{mm}^{2}$ which is indicated for M12 $\mathrm{x} 1.5$ bolt (ISO 261-1973). This upward progressive line terminates at $78.4 \mathrm{~N} . \mathrm{mm}^{2}$ which corresponds to M20 x 1.5 
bolt. The interpretation of this curve agrees with the earlier finding of this paper, that residual tolerance factor, $R_{t f}$ occurs with near negligible values upon the application of the required permissible stress. In addition, the fact that the permissible stress differentials in Table 1 for the range of bolts considered maintains a similarity with a negligible difference reinforces the position of this paper. Aggregately Fig 5 implies that this residual force limitation rises with increasing bolt size without regard to the values of M14 x 1.5 with $R_{t f}$ of $0.71 \mathrm{~N}$; which resulted a depression in Fig 4 and thus requiring further investigations.

However, Fig 4 is a 3-in-1 multiple graph indicating the inter-relationship between bolt size (top line), residual tolerance factor (middle line), and permissible stress (base line). Thus, the graph supports the argument that while $R_{t f}$ is dependent on bolt size, $P_{s}$ is a function of the tension in the bolt with respect to the area of specific impact. Hence, implying that an increase in bolt size results an increase of ingrained tension, which in this paper is viewed as permissible stress.

Further, it should be noted that the above modeling and calculation utilized a unified Stress Area of $362.1 \mathrm{~mm}^{2}$ for all the bolt sizes considered, due to the fact that it is supportive of the revolving clamp design reported in this paper. This implies that the calculations would be different for other stress areas corresponding to the various bolt sizes.

\section{Conclusion And Recommendations}

The study has considered the fundamental calculations required for the design of revolving clamp assembly which is a very important work tool in any well-equipped laboratory/ workshop.

The characteristics of this clamp compare well with the intended purpose of its design. Other types exist with limited scope of use and application; but the revolving clamp applies some flexibility for which a particular workpiece could be positioned and worked upon from different angles. The study also conducted a calculation of the stress capacity of the clamp, where it observed that the surface area of a clamp device i.e. the pad, plays a crucial role in its work holding capability. The yield stress was also determined alongside its bending and crushing stress.

As a recommendation for this study, it would be noted that the design of an engineering hardware such as the revolving clamp assembly should take into cognizance the need to cut cost while maintaining high precision and durability. Secondly, designs have to be made to serviceable specifications. That is to say that a particular piece of work tool or machine should not be designed to cause difficulty at the point of parts replacement or repairs. Thirdly, engineered items such as revolving clamp assembly should be designed to have some level of flexibility. This enhances high performance and reliability.

Fourthly, revolving clamp assembly should be fitly used alongside its screw support base with appropriate in-and-out washer fittings. By the use of this support base, the bolt attached to the stem of the clamp would be more effective in terms of positioning and precision.

Fifthly, it is of a significant concern that value engineering should be the focus of the design for this type of device, while considering the fact that although the $\mathrm{R}_{\mathrm{tf}}$ is a negligible but dependent factor, it could result a critical concern where it is used to hold an inappropriate workpiece at high speed machining operation, where stability is a crucial component of a zero defect manufacturing operation.

\section{References}

[1]. Vidosic, J.P. : Elements of Design Engineering, Ronal Press Co, New York, 1969

[2]. Design dimensions of screw threads, bolts and nuts according to IS 4218 (Part IV) 1978

[3]. Kalpakjian, S and Schmid, S.: Manufacturing Engineering and Technology, Pearson Education, 2001.

[4]. Rosentein, A.B. and English, J.M.,: Design as a Basis for a Unified Engineering Curriculum, Case Inst. Of Tech, Sept 8-9, 1960.

[5]. Reshetov, D, Ivanon A., Fadeev V, : Reliability of Machines, Mir Pub, Moscow, 1990,

[6]. Smith, R.B. : "Professional Responsibility of Engineering", Mechanical Engineering, v. 86, n.1 (Jan, 1964).

[7]. Aaron, D.D., Walter, J.M., Wilson, E.E.: machine Design- Theory and Practice, Macmillian Pub. Co. New York, 1975, pp 82-84

[8]. Avallone E.A. and baumeister III, .., : Standard Hand Book for Mechanical Engineers, 9 ${ }^{\text {th }}$ Ed, 1978. 